\title{
The Incentive Mechanism of the Subject Librarians with Computer Information Retrieval Under Competition
}

\author{
https://doi.org/10.3991/ijet.v16i10.22921 \\ Chunping Wang \\ Kunming University of Science and Technology, Kunming, China \\ Lili Song $(\bowtie)$ \\ Chongqing Three Gorges Vocational College, Wanzhou, China \\ songlili20130yeah. net
}

\begin{abstract}
Based on the H-M model, the optimal incentive model under competition was constructed, the best incentive system was constructed by solving the model, and its incentive characteristics are analyzed. Based on the theory of econometrics, an empirical model of incentive system was constructed, and the correlation and significance between the main core variables and incentive intensity are empirically tested. The results show that competition has a significant effect and positive effect on incentive level. Incentive level has a non-linear correlation with service cost and risk preference, within a certain range, the best incentive level is negatively related to them.
\end{abstract}

Keywords - Subject librarian, incentive level, incentive contract

\section{Introduction}

Computer science and technology literature information retrieval is offered by colleges and universities to improve information literacy of college students. Among them, information awareness and information ability are the core content of information literacy. This course introduces literature type, search field, search term, search operator, search strategy, search principle and many more to college students. Information retrieval needs retrieval platform to achieve. The retrieval system includes comprehensive, professional and multiple types databases. The retrieval platform database has its own search rules. Computer science and technology literature information retrieval learning will benefit the students a lot in their life and study. It can help students learn to use various databases to retrieve the information they need. Through learning computer literature information retrieval, college students are required to be able to determine the nature and scope of the information they need, grasp the existence of information sources, evaluate information and select useful information to solve difficult problems in life and study. The ultimate goal of computer literature information retrieval is to solve problems with information. 
Computer science and technology literature information retrieval teaching is foremost teaching task undertaken by the subject service team. The subject service team is a subject librarian group engaged in related subject services in university libraries. Subject librarians cooperate with each other and make full use of their skills and subject knowledge to provide users with in-depth subject knowledge services. With the continuous expansion of the content of subject education services, the subject service team mainly provides services for the administrative decision-making departments of universities, the departments where the key subjects are located, scientific researchers, key laboratories and bases through subject information analysis, training and teaching, subject resource promotion, teaching and research document resource construction, document resource retrieval and delivery, scientific and technological innovation, etc. Subject librarians are not only proficient in using various computer retrieval systems but also proficient in different data analysis tools. They are not only closely related to the construction of first-class disciplines in universities, but also very important.

Focusing on reality, an interview survey of nearly 1,000 subject librarians in more than 100 academic libraries directly revealed that the low compensation of subject librarians is the fundamental reason for the loss of attractiveness of subject services. Outstanding problems such as "insufficient incentives" faced by the subject service team have caused subject librarians to encounter problems such as insufficient intense emotion, low work enthusiasm, irresponsible attitude, and low service quality in subject service team. Therefore, it is very urgent and necessary to establish and improve the incentive system of subject service team.

Scholars mainly discuss the issue of subject librarian motivation from the theoretical and empirical levels. In terms of theoretical research, scholars mainly put forward a series of programs to effectively motivate subject librarians based on management incentive theory. Based on the comprehensive incentive theory, Yan [1] constructed an incentive model for the subject service team of academic libraries, analyzed its incentive process and characteristics. Wan [2] deeply analyzed the connotation of subject librarian's psychological contract and the mechanism of using psychological contract to encourage subject librarian, believed that psychological contract is a true reflection of subject librarian's needs and an important guarantee for effective motivation of subject librarian, and proposed that the enthusiasm and creativity of subject librarians can be continuously and effectively improved through development incentives, guarantee incentives, target incentives, trust incentives, and evaluation incentives, and the sustainable development of subject services can be realized. Wei [3] analyzed the current incentive situation and existing problems of subject librarians, and believed that a scientific, reasonable and feasible personalized incentive mechanism should be constructed based on demand to effectively motivate subject librarians and promote the development of the library business. Goodsett and Walsh [4] believed that unfamiliar academic and teaching requirements make librarians more anxious. Therefore, a tutoring plan can effectively encourage subject librarians to adapt to the new environment was proposed. Silva et al. [5] discussed how time and experience affect subject librarians' cognition of tenure, and found that providing academic librarians with tenure and teacher status is an effective way to attract and retain highquality subject librarians. 
In terms of empirical research, $\mathrm{Wu}$ [6] believed that personal achievement is a unique incentive element and the basis for designing an incentive mechanism. Combining the practice of subject librarians in subject knowledge services, Song [7] believed that subject librarians need 22 skills and knowledge to carry out subject knowledge services, and the rationality and necessity of these ability requirements have been proved again through investigation and research. Zhang et al. [8] collected data through questionnaires, drew lessons from the theoretical model of planned behavior, built a conceptual model of knowledge sharing influencing factors of academic library subject service teams in a media environment, and constructed a structural equation model for empirical testing. The accessibility, timeliness, and richness of shared knowledge of the library subject service team have been obtained, and the quality factor has a high impact on the knowledge sharing intention, and there is a positive effect. Tinuoye et al. [9] elaborate that job environment, salary level, fairness, professional title, academic promotion, learning and training have an important effect on the job satisfaction, the work efficiency and the high-quality service of the subject librarians. Silva and Galbraith [10] found that salary incentives are very important for subject service librarians through the questionnaire. The longer they have been engaged in the academic library, the higher the likelihood that they will consult for more salaries, and the likelihood of women take part in salary negotiations is often lower.

To sum up, from the existing literature on incentives for subject librarians, there are more qualitative studies based on management incentive theory, and fewer empirical studies. In particular, the existing empirical research is mainly realized through investigation and research methods, while the research on establishing empirical models based on real data for testing is relatively rare. Based on the theory of economic incentives-principle-agent theory, we construct an optimal incentive model for subject librarians in academic libraries, and analyze incentive characteristics through model solutions. And on the basis of theoretical research, we establish an incentive empirical model to test the correlation and significance between the incentive level and the main variables.

\section{Incentive Optimization Model}

\subsection{Basic assumptions}

Assumption 1: Subject librarians have two tasks, and they are independent each other. ei1 indicates the effort level of the subject librarian for the one task, and ei2 denotes the other effort level.

Assumption 2: Suppose the effort level of subject librarian i in different tasks is completely independent, and its service cost function is $C_{i}\left(e_{i 1}, e_{i 2}\right)=e_{i 1}{ }^{2} / 2 t_{1}+$ $e_{i 2}{ }^{2} / 2 t_{2}$, where a larger ti means a smaller service cost, and $\mathrm{i}=1,2$.

Assumption 3: Subject librarians are homogeneous. Subject librarians have a competitive relationship and the intensity of competition for the two tasks is the same. Therefore, the performance output functions of two subject librarians are respectively. 


$$
\begin{aligned}
& S_{11}=e_{11}+b\left(e_{11}-e_{21}\right)+\theta_{1} \\
& S_{12}=e_{12}+b\left(e_{12}-e_{22}\right)+\theta_{2} \\
& S_{21}=e_{21}+b\left(e_{11}-e_{21}\right)+\theta_{3} \\
& S_{22}=e_{22}+b\left(e_{12}-e_{22}\right)+\theta_{4}
\end{aligned}
$$

where, $\mathrm{b}$ is the user transfer coefficient, that is, the intensity of competition. $\theta \mathrm{i}$ represents uncontrolled exogenous randomness, and obeys a normal distribution and $\sigma_{i}^{2}>0, \mathrm{i}=1,2,3,4$.

The above expression contains the following two aspects.

1. When $\frac{\partial S_{i j}}{\partial e_{i j}}>0, i=1,2, j=1,2$ , it means that when the competitor's effort remains unchanged, and subject librarians increase their effort, the performance output will increase accordingly.

2. When $\frac{\partial S_{i j}}{\partial e_{i j}}<0, i=1,2, j=1,2$, it means that the effort level of the subject librarian remains unchanged, and the performance output of the subject librarian will be impaired with the increase of competitors' effort level.

Assumption 4: It is assumed that university administrators provide linear salary incentive $\omega_{i}=\alpha+b_{1} S_{i 1}+b_{2} S_{i 2}, i=1,2$ to supervise and motivate subject librarians to work hard. Where, ${ }^{\alpha}$ represents fixed salary, b1>0, b2>0 represent the service value sharing ratio.

Assumption 5: The subject librarians have an utility function $\mu\left(\omega, e_{1}, e_{2}\right)=-e^{-\rho\left[\omega-C\left(e_{1}, e_{2}\right)\right]}, \rho>0$ means that subject librarian is risk aversion, and the retained income for subject librarian to receive incentives is $\bar{u}$.

\section{$2.2 \quad$ Total social surplus}

1. Expected net income of managers

the expected income of the library managers is

$E\left(S_{11}+S_{12}+S_{21}+S_{22}\right)=e_{11}+e_{12}+e_{21}+e_{22}+2 b\left(e_{11}-e_{21}\right)+2 b\left(e_{12}-e_{22}\right)$

The expected benefits of subject librarians are

$$
\begin{aligned}
E\left(\omega_{1}\right) & =E\left(\alpha+b_{1} S_{11}+b_{2} S_{12}\right) \\
& =\alpha+b_{1} e_{11}+b_{1} b\left(e_{11}-e_{21}\right)+b_{2} e_{12}+b_{2} b\left(e_{12}-e_{22}\right)
\end{aligned}
$$




$$
\begin{aligned}
E\left(\omega_{2}\right) & =E\left(\alpha+b_{1} S_{21}+b_{2} S_{22}\right) \\
& =\alpha+b_{1} e_{21}+b_{1} b\left(e_{11}-e_{21}\right)+b_{2} e_{22}+b_{2} b\left(e_{12}-e_{22}\right)
\end{aligned}
$$

So, the expected net income of the library managers is

$$
\begin{aligned}
f_{p} & =E\left(S_{11}+S_{12}+S_{21}+S_{22}\right)-E\left(\omega_{1}\right)-E\left(\omega_{2}\right) \\
& =e_{11}+e_{12}+e_{21}+e_{22}+2 b\left(e_{11}-e_{21}\right)+2 b\left(e_{12}-e_{22}\right)-\alpha-b_{1} e_{11}-b_{1} b\left(e_{11}-e_{21}\right) \\
& -b_{2} e_{12}-b_{2} b\left(e_{12}-e_{22}\right)-\alpha-b_{1} e_{21}-b_{1} b\left(e_{11}-e_{21}\right)-b_{2} e_{22}-b_{2} b\left(e_{12}-e_{22}\right)
\end{aligned}
$$

\section{The CE of subject librarians}

According to the hypothesis, the expected net income of subject librarians is respectively

$$
\begin{aligned}
E\left(\omega_{1}\right)-C_{1}\left(e_{11}, e_{12}\right)=\alpha & +b_{1} e_{11}+b_{1} b\left(e_{11}-e_{21}\right)+b_{2} e_{12} \\
& +b_{2} b\left(e_{12}-e_{22}\right)-\frac{1}{2 t_{1}} e_{11}^{2}-\frac{1}{2 t_{2}} e_{12}^{2} \\
E\left(\omega_{2}\right)-C_{2}\left(e_{21}, e_{22}\right)=\alpha & +b_{1} e_{21}+b_{1} b\left(e_{11}-e_{21}\right)+b_{2} e_{22} \\
& +b_{2} b\left(e_{12}-e_{22}\right)-\frac{1}{2 t_{1}} e_{21}^{2}-\frac{1}{2 t_{2}} e_{22}^{2}
\end{aligned}
$$

Therefore, the CE of subject librarians are respectively

$$
\begin{aligned}
C E_{1}= & \alpha+b_{1} e_{11}+b_{1} b\left(e_{11}-e_{21}\right)+b_{2} e_{12}+b_{2} b\left(e_{12}-e_{22}\right) \\
& -\frac{1}{2 t_{1}} e_{11}^{2}-\frac{1}{2 t_{2}} e_{12}^{2}-\frac{1}{2} \rho b_{1}^{2} \sigma_{1}^{2}-\frac{1}{2} \rho b_{2}^{2} \sigma_{2}^{2} \\
C E_{2}= & \alpha+b_{1} e_{21}+b_{1} b\left(e_{11}-e_{21}\right)+b_{2} e_{22}+b_{2} b\left(e_{12}-e_{22}\right) \\
& -\frac{1}{2 t_{1}} e_{21}^{2}-\frac{1}{2 t_{2}} e_{22}^{2}-\frac{1}{2} \rho b_{1}^{2} \sigma_{1}^{2}-\frac{1}{2} \rho b_{2}^{2} \sigma_{2}^{2}
\end{aligned}
$$

3. Total social surplus

The total social surplus TS is defined as the sum of the manager's expected net income and the certainty equivalent income of the subject librarian:

$$
\begin{aligned}
T S & =e_{11}+e_{12}+e_{21}+e_{22}+2 b\left(e_{11}-e_{21}\right)+2 b\left(e_{12}-e_{22}\right) \\
& -\frac{1}{2 t_{1}} e_{11}^{2}-\frac{1}{2 t_{2}} e_{12}^{2}-\frac{1}{2 t_{1}} e_{21}^{2}-\frac{1}{2 t_{2}} e_{22}^{2}-\rho b_{1}^{2} \sigma_{1}^{2}-\rho b_{2}^{2} \sigma_{2}^{2}
\end{aligned}
$$

\subsection{Model construction, solution and analysis}

When the information is asymmetric, in order to achieve the best interests of both the manager and the subject librarian, the two conditions of participation constraint 
and incentive compatibility constraint must be met at the same time, so the incentive optimization model is shown below.

$$
\begin{cases}\max _{\overline{b_{1}}, \overline{b_{2}}, \bar{e}_{11}, \bar{e}_{12}, \bar{e}_{21}, \bar{e}_{22}, \bar{\alpha}} & \mathrm{e}_{11}+e_{12}+e_{21}+e_{22}+2 b\left(e_{11}-e_{21}\right)+2 b\left(e_{12}-e_{22}\right) \\ & -\frac{1}{2 t_{1}} e_{11}^{2}-\frac{1}{2 t_{2}} e_{12}^{2}-\frac{1}{2 t_{1}} e_{21}^{2}-\frac{1}{2 t_{2}} e_{22}^{2}-\rho b_{1}^{2} \sigma_{1}^{2}-\rho b_{2}^{2} \sigma_{2}^{2} \\ & \alpha+b_{1} e_{11}+b_{1} b\left(e_{11}-e_{21}\right)+b_{2} e_{12}+b_{2} b\left(e_{12}-e_{22}\right) \\ & -\frac{1}{2 t_{1}} e_{11}^{2}-\frac{1}{2 t_{2}} e_{12}^{2}-\frac{1}{2} \rho b_{1}^{2} \sigma_{1}^{2}-\frac{1}{2} \rho b_{2}^{2} \sigma_{2}^{2} \geq \bar{u} \\ & e_{11}, e_{12} \in \arg \max _{e_{11}, e_{12}} \alpha+b_{1} e_{11}+b_{1} b\left(e_{11}-e_{21}\right)+b_{2} e_{12} \\ & +b_{2} b\left(e_{12}-e_{22}\right)-\frac{1}{2 t_{1}} e_{11}^{2}-\frac{1}{2 t_{2}} e_{12}^{2}-\frac{1}{2} \rho b_{1}^{2} \sigma_{1}^{2}-\frac{1}{2} \rho b_{2}^{2} \sigma_{2}^{2} \\ & \alpha+b_{1} e_{21}+b_{1} b\left(e_{11}-e_{21}\right)+b_{2} e_{22}+b_{2} b\left(e_{12}-e_{22}\right) \\ & -\frac{1}{2 t_{1}} e_{21}^{2}-\frac{1}{2 t_{2}} e_{22}^{2}-\frac{1}{2} \rho b_{1}^{2} \sigma_{1}^{2}-\frac{1}{2} \rho b_{2}^{2} \sigma_{2}^{2} \geq \bar{u} \\ & e_{21}, e_{22} \in \arg \max _{e_{21}, e_{22}} \alpha+b_{1} e_{21}+b_{1} b\left(e_{11}-e_{21}\right)+b_{2} e_{22} \\ & +b_{2} b\left(e_{12}-e_{22}\right)-\frac{1}{2 t_{1}} e_{21}^{2}-\frac{1}{2 t_{2}} e_{22}^{2}-\frac{1}{2} \rho b_{1}^{2} \sigma_{1}^{2}-\frac{1}{2} \rho b_{2}^{2} \sigma_{2}^{2} \\ & \end{cases}
$$

where, (1) and (3) in the model respectively represent the participation constraint conditions; (2) and (4) respectively represent the incentive compatibility constraint conditions.

The above-mentioned incentive compatibility constraint conditions respectively seek the first-order conditions for the effort levels $e_{i 1}$ and $e_{i 2}$, then substitute them into the objective function in the model, and then seek the first-order conditions for the incentive intensity bi, and then the optimal salary incentive is $\left(\bar{\alpha}, \bar{b}_{1}, \bar{b}_{2}, \bar{e}_{1}, \bar{e}_{2}\right)$, that is

$$
\bar{\omega}_{i}=\bar{\alpha}+\bar{b}_{1} S_{i 1}+\bar{b}_{2} S_{i 2}, i=1,2
$$

where, the optimal sharing ratios are respectively

$$
\begin{aligned}
& \bar{b}_{1}=\frac{t_{1}\left(1+2 b^{2}\right)}{t_{1}\left(1+b^{2}\right)+\rho \sigma_{1}^{2}} \\
& \bar{b}_{2}=\frac{t_{2}\left(1+2 b^{2}\right)}{t_{2}\left(1+b^{2}\right)+\rho \sigma_{2}^{2}}
\end{aligned}
$$

The fixed salary of subject librarian is

$$
\begin{aligned}
\bar{\alpha} & =\bar{u}-b_{1} \bar{e}_{11}-b_{1} b\left(\bar{e}_{11}-\bar{e}_{21}\right)-b_{2} \bar{e}_{12}-b_{2} b\left(\bar{e}_{12}-\bar{e}_{22}\right) \\
& +\frac{1}{2 t_{1}} \bar{e}_{11}^{2}+\frac{1}{2 t_{2}} \bar{e}_{12}^{2}+\frac{1}{2} \rho b_{1}^{2} \sigma_{1}^{2}+\frac{1}{2} \rho b_{2}^{2} \sigma_{2}^{2}
\end{aligned}
$$


And the best effort levels of subject librarian are respectively

$$
\begin{aligned}
& \bar{e}_{11}=t_{1} \bar{b}_{1}(1+b) \\
& \bar{e}_{12}=t_{2} \bar{b}_{2}(1+b) \\
& \bar{e}_{21}=t_{1} \bar{b}_{1}(1-b) \\
& \bar{e}_{22}=t_{2} \bar{b}_{2}(1-b)
\end{aligned}
$$

By seeking partial guidance on the optimal incentive contract, the change trend of the optimal incentive intensity (service value sharing ratio) of subject librarians can be obtained with the change of competition intensity among subject librarians $b$, service cost $\mathrm{c}$, risk aversion level $\rho$, and randomness of the external environment $\sigma 2$. The changing trends of the factors are shown in Table 1.

Table 1. Trends of the core factors

\begin{tabular}{|c|c|c|c|c|}
\hline Incentive intensity & Competitive intensity $\boldsymbol{b} \uparrow$ & Risk aversion $\boldsymbol{\rho} \uparrow$ & Uncertainty $\boldsymbol{\sigma}^{2} \uparrow$ & Service cost $\boldsymbol{c} \uparrow$ \\
\hline$b_{1}$ & $\uparrow$ & $\downarrow$ & $\downarrow$ & $\downarrow$ \\
\hline$b_{2}$ & $\uparrow$ & $\downarrow$ & $\downarrow$ & $\downarrow$ \\
\hline
\end{tabular}

\section{Empirical Test}

\subsection{Variable description and model setting}

Variable description: The data required for the empirical research is obtained through questionnaires. Through statistical analysis, the data characteristics are as follows.

Table 2. Descriptive characteristics of variables

\begin{tabular}{|l|c|c|c|c|c|}
\hline Variables & Observations & Mean values & Maximum values & Minimum value & Standard deviations \\
\hline $\operatorname{Ln}(\operatorname{lnc})$ & 409 & 10.2854 & 12.2142 & 7.6824 & 0.6913 \\
\hline Com & 419 & 0.1227 & 0.5 & 0 & 0.0615 \\
\hline Cos & 413 & 7.8815 & 15 & 3.1090 & 1.9352 \\
\hline Ara & 316 & 0.0384 & 2.7603 & -0.7551 & 0.3828 \\
\hline Unc & 419 & 7.9116 & 15 & 1 & 5.2423 \\
\hline Lnfp & 411 & 6.9388 & 7.4955 & 6.2146 & 0.2645 \\
\hline Lndp & 411 & 6.3240 & 6.9077 & 5.7037 & 0.2528 \\
\hline Age & 419 & 9.6157 & 13 & 1 & 3.6605 \\
\hline
\end{tabular}


Table 3. Correlation analysis of variables

\begin{tabular}{|l|c|c|c|c|c|c|c|}
\hline \multicolumn{1}{|c|}{ Variables } & Com & LnCos & Ara & Unc & Lnfp & Lndp & Age \\
\hline Com & 1.0000 & & & & & & \\
\hline LnCos & 0.0115 & 1.0000 & & & & & \\
\hline Ara & -0.0122 & -0.0546 & 1.0000 & & & & \\
\hline Unc & -0.2710 & -0.0316 & 0.0754 & 1.0000 & & & \\
\hline Lnfp & -0.1888 & -0.0300 & -0.0510 & 0.3809 & 1.0000 & & \\
\hline Lndp & -0.1605 & -0.0350 & -0.0348 & 0.3702 & 0.7405 & 1.0000 & \\
\hline Age & -0.1401 & 0.0485 & -0.0673 & 0.0929 & -0.0182 & 0.0121 & 1.0000 \\
\hline
\end{tabular}

Model setting: We construct an empirical model composed of incentive level, competition intensity, service cost, risk preference and randomness of library external environment, and empirically tests the influence of the main core variables on the optimal incentive intensity (sharing ratio).

In the determination equation of incentive intensity, the core variables are competition level, service cost, risk preference and randomness of user choice, and the corresponding equations are constructed as follows.

$$
\begin{aligned}
& \operatorname{Ln}\left(\operatorname{Inc}_{i t}\right)=\alpha+\beta_{1} \operatorname{Com}_{i t}+\beta_{2} \operatorname{Ln} \operatorname{Cos}_{i t}+\beta_{3} \operatorname{Ara}_{i t}+\beta_{4} U n c_{i t}+\varepsilon_{i t} \\
& \operatorname{Ln}\left(\operatorname{Inc}_{i t}\right)=\alpha+\beta_{1} \operatorname{Com}_{i t}+\beta_{2}\left(\operatorname{Ln} \operatorname{Cos}_{i t}\right)^{2}+\beta_{3} \operatorname{Ln} \operatorname{Cos}_{i t} \\
& +\beta_{4}\left(\text { Ara }_{i t}\right)^{2}+\beta_{5} A_{r a}+\beta_{6} U n c_{i t}+\varepsilon_{i t} \\
& \operatorname{Ln}\left(\operatorname{Inc}_{i t}\right)=\alpha+\beta_{1} \operatorname{Com}_{i t}+\beta_{2}\left(\operatorname{Ln} \operatorname{Cos}_{i t}\right)^{3}+\beta_{3}\left(\operatorname{Ln} \operatorname{Cos}_{i t}\right)^{2} \\
& +\beta_{4} \operatorname{Ln} \operatorname{Cos}_{i t}+\beta_{5}\left(A r a_{i t}\right)^{2}+\beta_{6} A r a_{i t}+\beta_{7} U n c_{i t} \\
& +\beta_{8} \operatorname{Ln}\left(f p_{i t}\right)+\beta_{9} \operatorname{Ln}\left(d p_{i t}\right)+\varepsilon_{i t} \\
& \operatorname{Ln}\left(\operatorname{Inc}_{i t}\right)=\alpha+\beta_{1} \operatorname{Com}_{i t}+\beta_{2}\left(\operatorname{Ln} \operatorname{Cos}_{i t}\right)^{3}+\beta_{3}\left(\operatorname{Ln} \operatorname{Cos}_{i t}\right)^{2} \\
& +\beta_{4} \operatorname{Ln} \operatorname{Cos}_{i t}+\beta_{5}\left(\text { Ara }_{i t}\right)^{2}+\beta_{6} \text { Ara }_{i t}+\beta_{7} U n c_{i t} \\
& +\beta_{8} \operatorname{Ln}\left(f p_{i t}\right)+\beta_{9} \operatorname{Ln}\left(d p_{i t}\right)+\beta_{10} A g e_{i t} * D u m_{i t}+\varepsilon_{i t} \\
& \operatorname{Ln}\left(\operatorname{Inc}_{i t}\right)=\alpha+\beta_{1} \operatorname{Com}_{i t}+\beta_{2}\left(\operatorname{Ln} \operatorname{Cos}_{i t}\right)^{3}+\beta_{3}\left(\operatorname{Ln} \operatorname{Cos}_{i t}\right)^{2} \\
& +\beta_{4} L n \operatorname{Cos}_{i t}+\beta_{5}\left(A r a_{i t}\right)^{2}+\beta_{6} A r a_{i t}+\beta_{7} U n c_{i t} \\
& +\beta_{8} \operatorname{Ln}\left(f p_{i t}\right)+\beta_{9} \operatorname{Ln}\left(d p_{i t}\right)+\beta_{10} A g e_{i t} * D u m_{i t} * U n c_{i t} \\
& +\varepsilon_{i t}
\end{aligned}
$$

In the above economical empirical model, the intensity of competition is measured by the ratio of annual quantity of one novelty search to the total annual quantity of all. Com represents the intensity of competition. Other core variable detailed measurements can be find in the reference [12]. 


\subsection{Analysis of empirical results}

Based on the constructed empirical model, we empirically test the influence of competition intensity, service cost, risk aversion, and the uncertainty of the external environment on incentive level after running the measurement software Stata14.0. The empirical tests are the following Table 4.

Table 4. Correlation regression analysis of core variables under competition intensity

\begin{tabular}{|c|c|c|c|c|c|}
\hline Core Variables & Model 1 & Model 2 & Model 3 & Model 4 & Model 5 \\
\hline \multirow{2}{*}{ Com } & $2.5414^{* * *}$ & $2.5830^{* * *}$ & $3.2960^{* * *}$ & $3.3297^{* * *}$ & $3.3151^{* * *}$ \\
\hline & $(4.42)$ & $(4.6)$ & $(6.59)$ & $(6.69)$ & $(6.68)$ \\
\hline \multirow{2}{*}{$(\operatorname{LnCos})^{3}$} & & 0.6379 & 1.4805 & 1.4172 & 1.4176 \\
\hline & & $(0.6)$ & $(1.57)$ & $(1.51)$ & $(1.52)$ \\
\hline \multirow{2}{*}{$(\operatorname{LnCos})^{2}$} & & -3.2853 & -8.1934 & -7.6492 & -7.6145 \\
\hline & & $(-0.53)$ & $(-1.5)$ & $(-1.41)$ & $(-1.40)$ \\
\hline \multirow{2}{*}{$\operatorname{Ln} \mathrm{Cos}$} & 0.1221 & 5.4926 & 15.0260 & 13.6333 & 13.4677 \\
\hline & $(0.62)$ & $(0.46)$ & $(1.43)$ & $(1.31)$ & $(1.29)$ \\
\hline \multirow{2}{*}{$A r a^{2}$} & & $-0.2589^{* * *}$ & $-0.2836^{* * *}$ & $-0.2864^{* * *}$ & $-0.2830^{* * *}$ \\
\hline & & $(-4.43)$ & $(-5.27)$ & $(-5.31)$ & $(-5.26)$ \\
\hline \multirow[t]{2}{*}{ Ara } & $0.1512^{* *}$ & $0.3723^{* * *}$ & $0.4388^{* * *}$ & $0.4417^{* * *}$ & $0.4387^{* * *}$ \\
\hline & $(2.42)$ & $(4.74)$ & $(6.09)$ & $(6.12)$ & $(6.10)$ \\
\hline \multirow{2}{*}{ Unc } & $0.0208^{*}$ & $0.0226^{* *}$ & -0.0048 & -0.0066 & $-0.0190 *$ \\
\hline & $(1.79)$ & $(2.06)$ & $(-0.52)$ & $(-0.72)$ & $(-1.69)$ \\
\hline \multirow{2}{*}{ Lnfp } & & & $0.7390^{* * *}$ & $0.6798^{* * *}$ & $0.6601^{* * *}$ \\
\hline & & & $(3.61)$ & $(3.30)$ & $(3.21)$ \\
\hline \multirow{2}{*}{ Lndp } & & & $0.7682^{* * *}$ & $0.8279^{* * *}$ & $0.8486^{* * *}$ \\
\hline & & & $(3.54)$ & $(3.8)$ & $(3.89)$ \\
\hline \multirow[t]{2}{*}{ Age*Dum } & & & & $0.0146^{*}$ & \\
\hline & & & & $(1.72)$ & \\
\hline \multirow[t]{2}{*}{ Age $*$ Dum $*$ Unc } & & & & & $0.0020^{* *}$ \\
\hline & & & & & $(2.17)$ \\
\hline Within $R^{2}$ & 0.0703 & 0.1272 & 0.2630 & 0.2609 & 0.2606 \\
\hline Between $R^{2}$ & 0.1396 & 0.2378 & 0.4757 & 0.4945 & 0.5014 \\
\hline Overall $R^{2}$ & 0.1338 & 0.1910 & 0.3780 & 0.4068 & 0.4258 \\
\hline$N$ & 315 & 315 & 315 & 315 & 315 \\
\hline
\end{tabular}

$* * *, * *, *$ Indicate that the core variables are significant at the level of $1 \%, 5 \%, 10 \%$, respectively.

\section{Conclusion}

Based on the conclusions of incentive theory, we collect relevant data of subject librarian of novelty retrieval, constructs an empirical model of incentive intensity that 
includes competition intensity, and empirically tests the significance and correlation between the main core variables and incentive intensity. Through empirical analysis, the following important conclusions are obtained.

1. In the incentive system designed by the manager, the incentive intensity implemented by the manager to the subject librarian, that is, the value sharing ratio obtained is closely related to four factors of competitive relationship among subject librarians, subject service cost, risk avoidance degree, and randomness of entrusting clients to choose subject services.

On the one hand, it is recommended to learn from the successful experience and practices of enterprises and other organizations, and implement an income distribution system for subject librarians with fixed income plus subject service value sharing. The proportion of value sharing mainly depends on the comprehensive technical ability of the subject librarian, the mutual relationship, the service cost, the degree of risk aversion, and the uncertainty of the external environment. On the other hand, managers should choose subject librarians with high-risk preferences, high comprehensive technical capabilities, and low unit effort costs. Subject librarians with higher risk aversion will reduce their own risk and effort in order to reduce their own level of effort, which will damage the service output of the institution. However, subject librarians with higher comprehensive technical level and lower unit effort cost have a higher degree of effort, which will increase the service output of subject service institutions. At the same time, managers can train subject librarians to achieve a win-win situation.

2. The intensity of competition has a significant effect on the incentive. The higher competition, the more intense the competition for subject librarians. Therefore, managers should strengthen incentives to achieve a win-win. The relationship between subject librarians will affect the service output of subject librarians. Before designing a salary incentive system, managers should evaluate multiple tasks undertaken by subject librarians based on the relevance of tasks, determine the relevant attributes and interrelationship characteristics between subject librarians based on the optimal incentive contract, and can strengthen the mutual relationship between subject librarians by setting up a reward and punishment system.

3. The service cost has little effect on the incentive level, and the relationship between incentive level and service cost is not a linear relationship, but a complex nonlinear relationship. In a certain range, the higher the service cost, in order to maximize the expected benefits of managers, managers should weaken incentive.

4. The risk aversion has a significant effect on the incentive level, and the relationship between incentive level and risk aversion is not a linear relationship, but a quadratic correlation. Within a certain range, the higher risk aversion, the more risk that they are afraid of. In order to meet the managers' expectation of the best returns, managers will weaken the incentives for subject librarians.

5. The uncertainty of the external environment of the library, that is, the randomness of entrusting clients to select subject services, has a high effect on the incentive, and there is a negative effect with it. That is, the higher the randomness of service selection, the manager should reduce the sharing ratio of subject librarians. 


\section{Acknowledgement}

This work was supported in part by Talent Training Project of Kunming University of Science and Technology (Grant No. KKSY201814014), Planning Project of Yunnan Provincial Philosophy and Social Sciences (Grant No. QN2018046).

\section{References}

[1] Yan, Q.J. (2017). Research on incentive mechanism of subject service team in university library based on synthesizing motivation theory. Journal of Library and Information Sciences in Agriculture, 29(12), 212-214.

[2] Wan, W.J. (2017). Research on the motivation of library subject librarians from the perspective of psychological contract. Research on Library Science, (20), 97-101.

[3] Wei, G.G. (2013). Construction of a demand-oriented incentive mechanism for university subject librarians. Library \& Information Studies, 6(3), 50-53.

[4] Goodsett, M., Walsh, A. (2015). Building a strong foundation: Mentoring programs for novice tenure-track librarians in academic libraries. College \& Research Libraries, 76(7), 914-933. https://doi.org/10.5860/crl.76.7.914

[5] Silva, E., Galbraith, Q., Groesbeck, M. (2017). Academic librarians' changing perceptions of faculty status and tenure. College \& Research Libraries, 78(4), 428. https://doi.org/10. $\underline{5860 / \mathrm{crl} .78 .4 .428}$

[6] Wu, H.W. (2014). Discussion on the incentive factor of subject librarian. Journal of Library and Information Sciences in Agriculture, 26(4), 193-196.

[7] Song, J.F. (2015). The construction and empirical study of subject knowledge service ability of subject librarian. Journal of Academic Library, 33(3), 68-76.

[8] Zhang, X.X., Guo, S.L., Li, K. (2017). Influencing factors and empirical research on knowledge sharing of library subject service team in the new media environment. Research on Library Science, (13), 50-58.

[9] Tinuoye, G.O.O., Omeluzor, S.U., Akpojotor, L.O. (2016). Factors influencing job satisfaction of academic librarians in university libraries in edo and delta states, Nigeria. Electronic Library, 34(6), 985-996. https://doi.org/10.1108/EL-07-2015-0128

[10] Silva, E., Galbraith, Q. (2018). Salary negotiation patterns between women and men in academic libraries. College \& Research Libraries, (79)3, 324-335. https://doi.org/10. $\underline{5860 / \mathrm{crl} .79 .3 .324}$

[11] Jing, J. (2019). Investigation and analysis on the construction of subject service teams in chinese university libraries. Library and Information Service, 63(17), 103-109. https:// doi.org/10.13266/j.issn.0252-3116.2019.17.012

[12] Wang,C.P., Song L.L. (2021). The incentive mechanism of the subject librarians in the university library. International Journal of Emerging Technologies in Learning, 16(3), 114126.

[13] John, K., Litov, L., Yeung, B. (2008). Corporate governance and risk-taking. The Journal of Finance, 63(4), 1679-1728. https://doi.org/10.1111/j.1540-6261.2008.01372.x

[14] Boubakri, N., Cosset, J.C., Saffar, W. (2013). The role of state and foreign owners in corporate risk-taking: Evidence from privatization. Journal of Financial Economics, 108(3), 641-658. https://doi.org/10.1016/j.jfineco.2012.12.007 
[15] Faccio, M., Marchica, M.T., Mura, R. (2011). Large shareholder diversification and corporate risk-taking. Review of Financial Studies, 24(11), 3601-3641. https://doi.org/ $\underline{10.1093 / \mathrm{rfs} / \mathrm{hhr} 065}$

[16] Holmstrom, B., Milgrom, P. (1991). Multi-task principal-agent problems:incentive contracts,asset ownership, and job design. Journal of Law, Economics and Orgnanization, 7, 24-52. https://doi.org/10.1093/jleo/7.special issue.24

[17] Holmstrom, B., Milgrom, P. (1987). Aggregation and Linearity in the Provision of intertemporal Incentive. Econometrica, 55, 303-328. https://doi.org/10.2307/1913238

[18] Holmström, B., Milgrom, P. (1990). Regulating trade among agents. Journal of Institutional and Theoretical Economics, 85-105.

[19] Holmstrom, B. (1979). Moral hazard and observability. Bell Journal of Economics, 10(1), 74-91.

[20] Itoh, H. (1991). Incentives to help in multi-agent situations. Econometrica: Journal of the Econometric Society, 611-636. https://doi.org/10.2307/2938221

[21] Slade, M. E. (1996). Multitask agency and contract choice: An empirical exploration. International Economic Review, 465-486. https://doi.org/10.2307/2527333

[22] McAfee, R. P., McMillan, J. (1991). Optimal contracts for teams. International Economic Review, 561-577.

[23] Baker, G. (1992). Incentive contracts and performance measurement. Journal of Political Economy, 100(3), 598-614. https://doi.org/10.1086/261831

\section{$7 \quad$ Authors}

Chunping Wang is a member of Library, Kunming University of Science and Technology, Kunming 650500, China, Email: wcptsg@126.com. Her research interests include computer information retrieval and principal-agent.

Lili Song is a member of School of Economics and Management, Chongqing Three Gorges Vocational College, Chongqing 404155, China, Email: songlili2013@yeah.net. Her research interests include human resource management and marketing.

Article submitted 2021-02-26. Resubmitted 2021-04-13. Final acceptance 2021-04-14. Final version published as submitted by the authors. 